\title{
Context-Dependent Metaphor Comprehension Ability of School-Aged Children with Borderline Intellectual Functioning
}

\author{
Yun Ji Kwak, Mina Hwang ${ }^{\mathrm{b}}$, Miran Jeong \\ ${ }^{a}$ Department of Speech and Language Pathology, Graduate School, Dankook University, Yongin, Korea \\ ${ }^{b}$ Department of Special Education, Dankook University, Yongin, Korea \\ 'Department of Speech-Language Therapy, U1 University, Youngdong, Korea
}

Correspondence: Miran Jeong, PhD Department of Speech-Language Therapy, U1 University, 310 Daehak-ro, Yeongdong-eup, Yeongdong-gun, Chungcheongbuk-do 29131, Korea

Tel: +82-43-740-1631

Fax: +82-43-740-1179

E-mail: jmr370@yd.ac.kr

Received: July 5, 2016

Revised: August 16, 2016

Accepted: August 22, 2016

This work is based on the master's thesis of the first author.

\begin{abstract}
Objectives: The purpose of the present study was to investigate the metaphor comprehension ability of school-aged children with borderline intellectual functioning (BIF) and typically developing (TD) children. Methods: Children with BIF who were language-age 7 to $8(\mathrm{~N}=10)$ and TD children with matched language age $(\mathrm{N}=10)$ participated in this study. To examine their metaphor comprehension ability depending on contextual condition, two tasks were performed, based on the following conditions: a non-contextual condition presenting only metaphorical sentences (18 items) and a contextual condition presenting contexts in the form of a short conversation (18 items). The children were instructed to choose an answer to each question among three example choices (correct interpretation choice, literal error choice including vehicle, and irrelevant choice). Results: A two-way mixed ANOVA of group (2) $\times$ context condition (2) revealed statistically significant main effects for group and context condition. There was also a significant interaction effect. Conclusion: The children with BIF had more difficulty comprehending metaphor as compared with the TD children. These results imply that the children with BIF were less capable of inferring the meaning of metaphor than TD children. In a conversational linguistic context, both children with BIF and TD performed better than in a non-contextual condition. The implications and limitations of the study were discussed based on these results.
\end{abstract}

Keywords: Borderline intellectual functioning, Metaphor, Context
비유 언어(figurative language)는 문자적인 의미 이외에 감추어 진 의미를 담고 있는 언어 표현으로, 은유, 직유, 관용어 등을 들 수 있는데(Owens, 2005), 은유(metaphor)는 비유 언어 중 가장 대표 적인 표현 방식이라 할 수 있다(Leonard, 1998). 은유는 일상생활의 자연스런 구성요소라 할 만큼 사람들은 무의식적으로 은유를 사 용하며 순간적으로 이해하기도 한다. 또한 은유는 인지, 지식의 구 성 그리고 의사소통의 핵심 요소로 이해되지만, 은유에 대한 이해 와 표현능력은 개인에 따라 매우 다르다(Tan, Barbot, Mourgue, \& Grigorenko, 2013). 은유가 일상생활에 녹아 있는 만큼 의사소통 을 보다 효과적으로 하기 위해서는 언어가 가진 표면적인 의미뿐만 아니라 숨겨진 의미를 이해하고 표현할 수 있는 능력이 필요하다.
연령이 증가할수록 책, TV 광고, 음악 등을 통하여 자연스럽게 접 하게 되고 교과서나 또래 혹은 성인과의 대화에서 은유에 대한 노 출이 증가하게 된다. 유아기를 거쳐 학령기에 든 아동들은 또래와 의 대화에서 유능한 대화상대자가 되기 위해서나 사회인으로 성장 해 나가는 데 있어서 은유를 이해하고 표현하는 능력이 점차 중요 해진다(Lazar, Warr-Leeper, Nicholson, \& Johnson, 1989).

은유는 '나비는 무지개다.' 처럼 'A는 B다' 라는 기본적인 형태를 가진다. 여기서 $\mathrm{A}$ 는 '주제어(topic)'로 비유하는 대상이고 $\mathrm{B}$ 는 '매개 어(vehicle)'로 비유되는 대상이다(Nippold \& Fey, 1983). 은유를 이 해하기 위해서는 비교하고 범주화하고 평가할 수 있는 사고력뿐만 아니라 $\mathrm{A}$ 와 $\mathrm{B}$ 가 의미하는 문자적인 의미와 비유적인 의미를 연결 
Yun Ji Kwak, et al. • Metaphor Comprehension of School-Aged Children with Borderline Intellectual Functionling

하여 대응시킬 수 있는 능력이 필요하다(Nippold \& Fey, 1983; Tan et al., 2013). 또한 화자의 의도를 파악할 수 있는 마음읽기 능력, 배 경지식, 연령, 인지능력, 추론능력 등 다양한 능력이 요구된다(Malgady, 1977; Masi, Marcheschi, \& Pfanner, 1998; Nippold, 2007; Seo, 1982; Vosniadou, 1989).

초기 연구자들은 주로 은유를 이해하는 시기에 초점을 맞춘 연 구를 진행하였다. 은유 이해 능력의 발현시기에 대한 연구자들의 입장은 일치하지 않으나 은유 이해 능력은 인지능력의 발달과 함께 진행되는 것으로 만 7-10세 정도에 은유적 해석이 빈번하게 일어나 며 이후 성인기까지 점진적으로 진행된다고 하였다(Billow, 1975; Hong, 2001; Seo, 1982; Siltanen, 1989). 이후 맥락이 제공되거나 은 유의 종류에 따라 더욱 어린 연령에서도 은유 이해가 가능하다는 결과들이 보고되었다(Byun \& Choi, 2000; Highnam, Wegmann, \& Woods, 1999; Vosniadou, 1989). 이러한 연구성과는 은유의 이 해에 영향을 주는 연구로 발전되어 은유의 종류, 유형, 친숙도 또는 맥락의 종류에 따라 은유의 이해와 표현의 발달시기를 알아보거나 아울러 단순언어장애, 학습장애, 읽기장애 아동 등 다양한 특성의 아동들과 일반아동의 은유 이해와 표현능력을 비교하는 연구로 확장되어 왔다(Cha, 2006; Heo, Lim, \& Hwang, 2012; Kim, 2002; Kim, Hwang, \& Ko, 2016; Lee \& Kim, 2015; Norbury, 2005; Reynolds \& Ortony, 1980; Shin \& Kwon, 2010).

은유의 이해에 영향을 주는 요인은 매우 다양하다. 개인이 지닌 능력에 의해서 영향을 받을 뿐 아니라 외적으로는 은유의 종류, 구 문구조, 문맥 등의 영향을 받게 된다(Byun \& Choi, 2000; Heo et al., 2012; Highnam et al., 1999; Shin \& Kwon, 2010; Vosniadou, 1989). 이러한 요인들은 상대방의 언어가 문자적 표현인지 은유적 표현인지를 구분해 주고, 은유적 표현이 함축하고 있는 의미에 대 한 단서를 제공해준다(Chung, 2002).

많은 연구자들이 은유를 이해하는 데 있어서 문맥의 영향을 연 구하였다. 특히 Vosniadou (1989)는 문맥(context)을 화자와 청자 를 묶어 주는 공통의 배경(common ground)이라 정의하고 이는 특 히 청자가 화자의 발화를 이해하기 위해 알아야 하는 공통의 배경 이라 강조하였다. 그는 문맥을 내적인(intrinsic) 문맥과 외적인(extrinsic) 문맥으로 구분하여 내적 문맥은 화자의 배경 지식에 의존 하는 것으로 스크립트, 쉐마, 정신적 모델 등으로 불리는 기억에 저 장된 지식이라 하였다. 외적인 문맥이란 물리적 환경을 의미하는 상황적(situational) 문맥과 화자와 청자가 이미 진행한 언어적 의사 소통으로 공유하는 언어적(linguistic) 문맥으로 구성된다고 하였 다. 이와 같이 문맥은 매우 광범위한 영역을 포함할 수 있는데, 연구 자들은 외적 문맥의 영향을 주로 연구하였다. 어린 아동들은 언어
적 문맥보다는 놀잇감과 모형을 제공하여 상황을 재현한 상황적 문맥에서 은유를 더 잘 이해하였다고 하면서, 은유에 대한 이해는 제공된 언어적 정보와 외적 문맥의 영향을 모두 받는다고 하였다 (Vosniadou, 1989). 문맥을 시각적인 것과 언어적인 것으로 구분하 여 비교한 연구에서 아동들의 경우 언어적 문맥에 비해 시각적 문 맥에서 은유를 더 잘 이해하는 것으로 나타났다(Highnam et al., 1999; Seo, 1982). 한편 언어적 문맥이 제공되지 않고 은유만 제공되 는 조건과 설명하기나 짧은 이야기 등의 언어적 문맥이 제공되는 조건을 비교한 결과, 언어적 문맥은 은유 이해에 도움이 되는 것으 로 나타났다(Byun \& Choi, 2000; Cha, 2006; Heo et al., 2012; Highnam et al., 1999; Reynolds \& Ortony, 1980; Shin \& Kwon, 2010; Vosniadou, 1989). 이러한 연구결과들을 종합해 보면, 문맥은 연구 자에 따라 다르게 구분되기도 하지만, 일반아동뿐 아니라 학령기 에 언어발달에 어려움을 겪거나 학습에 어려움을 겪는 다양한 아 동들의 은유 이해를 촉진하는 역할을 할 수 있으며 문맥은 일상생 활과 유사할 때 더욱 도움이 될 수 있음을 추측할 수 있다.

경계선 지능(borderline intellectual functioning, BIF) 아동은 학 령기에 들어서 학습이나 또래와의 소통에서 어려움을 겪는 경우가 많다. 이들은 정신지체로 진단 받지 않았으나 지적능력이 70-84인 아동을 뜻한다(Diagnostic and Statistical Manual of Mental Disorders fourth edition, DSM-IV; American Psychiatric Association, 2000). 이들은 정신지체 아동과 달리 일상적인 대화 상황에서 크게 문제가 드러나지 않기 때문에 학령기 이전에는 조금 발달이 늦은 아이로 인식되기 쉽고 언어발달의 지체로 치료를 받는다 하더라도 지적장애 아동만큼 심각한 문제를 지닌 아동으로 인식되지 않는 다. 하지만 이들은 취학 후 학령기를 거치면서 학습적인 문제를 보 이게 되고 언어적 어려움이 더욱 심화된다. 경계선 지능 아동은 그 들이 보이는 언어 및 학습문제로 인하여 일반아동과 구별되며 다른 한편으로는 지적장애 아동과도 구별되는, 특별한 교육적 지원과 치료지원 서비스가 필요하다는 점에서 분명 위험군이라는 인식이 확산되면서 이들에 대한 관심이 증가하고 있다(Jung \& Lee, 2005; Kim, 2012; Kim, 2015; Kim \& Kim, 2007; Lim \& Hwang, 2006; Madden \& Slavin, 1983; Masi et al., 1998; Yu, Jeong, \& Kim, 2007). 경계선 지능 아동은 인지영역에서 낮은 기능을 보였고 학업성취 도가 매우 낮았으며 학년이 올라갈수록 학업 성취 정도가 일반아 동에 비해 상대적으로 더 떨어지게 되어 고학년이 될수록 일반아 동과의 차이가 점차적으로 증가하였다(Jung \& Lee, 2005; Kim \& $\mathrm{Kim}, 2007)$. 정서, 행동면에서는 사회적 미성숙, 집중력 부족과 소 외감을 보이는 것으로 나타났으며, 학령전기 아동은 우울감과 소 외감을, 저학년 아동들은 공격성, 충동성의 정서문제가 높은 것으 
로 나타났으며 언어성 지능이 우세한 일부 아동은 우울 및 불안행 동이 나타났다(Jung \& Lee, 2005).

언어적 측면에서 경계선 지능 아동은 여러 영역에서 문제가 있음 이 보고되었다. 표준화된 검사를 통해 알아본 수용어휘력이 일반 아동에 비해 지체되었고(Yu et al., 2007), 7-9세 초등 2-4학년 경계 선 지능 언어발달장애 아동의 구문인식능력을 조사한 결과 이들 은 조사오류에 대한 판단능력이 일반아동보다 지체되었으며 $(\mathrm{Lim}$ \& Hwang, 2006), 8-9세 경계선 언어발달지체 아동은 문장따라말 하기 과제를 사용한 구문능력 평가에서 생활연령 일치 아동에 비 해서는 유의하게 지체되었으나 언어연령 일치 아동과는 유사한 수 행력을 보였다(Kim, 2012). 읽기영역에서는 표준화된 검사도구를 통해 평가한 결과, 경계선 지능 저학년과 고학년, 그리고 평균지능 저학년 간에는 해독(decoding)과제 수행에서 유의한 차이가 나타 나지 않았다(Kim \& Kim, 2016). 그리고 10-11세의 경계선 지능 아 동은 언어연령을 일치시킨 일반아동에 비하여 관용어 이해능력이 유의하게 저조하였는데, 두 집단 아동 모두 문맥을 제공한 경우 관 용어 이해를 위한 의미 추론을 더 잘 하였으며 특히, 경계선 지능 아동은 문맥이 제시되었을 때 과제 수행력이 급격히 향상되었다 (Kim, 2015). 한편 경계선 지능 아동이 새로운 단어의 의미를 추론 하는 능력을 조사한 연구결과를 보면, 단어의 정의를 제공한 경우 와 문맥을 제공한 경우에 일반아동은 두 조건에서 수행력이 유사 하였으나 경계선 지능 아동은 정의 제공 조건에 비해 문맥 제공 조 건에서 다소 낮은 수행을 보여, 문맥을 잘 활용하지 못하는 것으로 나타났다(Kim et al., 2016). 이들은 학업 성취를 위해 요구되는 추 론, 논리적 판단, 오류수정 등과 같은 상위언어능력의 결함이나 화 용능력의 결함도 함께 보이며(Masi et al., 1998; Reis, McGuire, \& $\mathrm{Neu}, 2000$ ), 특히 화용적인 측면의 결함으로 인해 적절한 상황파악 및 대처기술이 부족하여 또래관계에 어려움을 보이고 사회적 부적 응 문제를 겪게 되기도 한다(Jung \& Lee, 2005; Lim, 2010; Madden \& Slavin, 1983).

이상의 연구결과를 요약해 보면, 경계선 지능 아동은 기초적인 언어능력뿐만 아니라 학습능력의 결함, 상위언어능력의 결함을 함 께 보이며 전반적으로 일반아동의 발달과정을 밟아가지만 그 속도 는 느린 것을 알 수 있다. 또한 새로운 지식이나 정보를 습득함에 있 어서 문맥의 도움을 받기도 하지만 과제의 특성에 따라 달라질 수 있음도 알 수 있다. 이들은 학년이 높아질수록 취약한 상위언어능 력이나 화용적 결함으로 인해 일상생활에서 자주 접하게 되는 비 유적 표현을 적절히 해석하지 못하게 되고 이러한 경험의 축적은 성인으로 성장해 갈수록 유능한 대화상대자로서의 기능을 수행하 기가 어렵게 될 가능성이 높아진다.
본 연구에서는 경계선 지능 아동과 언어연령 일치 일반아동을 대상으로 보다 일상적 상황에 가까운 문맥을 제공하고자 대화식의 언어적 문맥을 제공하여 비문맥 조건과 문맥 조건에 따른 은유 이 해능력을 살펴보고자 하였다. 선행연구들은 주로 설명하기나 이야 기 문맥을 제공하였는데 이러한 문맥들은 일상적으로 접하는 언어 적 문맥으로 의미가 있었다. 아동에 대한 중재에서는 다양한 문맥 을 제공할 필요가 있으므로, 본 연구에서는 언어적 문맥의 다양화 라는 측면에서 가능한 일상생활에 근접한 대화상황의 언어적 문 맥을 제공하여 두 집단의 은유 이해 수행력을 비교하였다. 이를 통 하여 이들에 대한 은유 중재활동을 확장하는 데 일조하기를 기대 한다.

\section{연구 방법}

\section{연구 대상}

은유 이해에 대한 발달연구에서 제시한 바를 참고하여(Billow, 1975; Hong, 2001; Seo, 1982), 언어연령 만7세 이상을 대상으로 하 였다. 언어연령이 7-8세인 경계선 지능 아동 10 명과 언어연령을 일 치시킨 일반아동 10 명, 총 20 명이 본 연구에 참여하였다. 두 집단 모 두 서울 및 경기 지역에 거주하는 아동으로, 경계선 지능 아동은 일 반 학교, 치료 교육기관, 지역아동센터에서 모집하였고 일반아동은 일반학교, 지역아동센터에서 모집하였다.

경계선 지능 아동은 (1) 한국-웩슬러 아동지능검사(Korean-Wechsler Intelligence Scale for Children-III, K-WISC-III; Kwak, Park, \& $\mathrm{Kim}, 2001)$ 결과 전체지능이 경계선 지능(IQ 70-84)에 해당되고, (2) 수용 - 표현 어휘력검사(Receptive Expressive Vocabulary Test, REVT; Kim, Hong, Kim, Jang, \& Lee, 2009)의 표현어휘 등가연령 이 7;0-8;11세 범위에 해당하며, (3) 구문의미이해력검사(Pae, Lim, Lee, \& Jang, 2004)의 원점수가 7세 평균을 기준으로 -1 SD 이상이 며, (4) 교사나 부모에 의해 약물을 복용하거나 기타 신체, 행동, 정 서, 심리 등에서 장애로 진단 받은 적이 없고, (5) 일반학급에 재학 중인 아동으로 선정하였다.

언어연령 일치 일반아동은 (1) 한국-웩슬러 아동지능검사(KWISC-III; Kwak et al., 2001) 결과 전체지능이 정상범주(IQ 85 이상) 이며, (2) 수용·표현 어휘력검사(REVT; Kim et al., 2009) 결과 표현 어휘의 등가연령이 7;0-8;11세 범위에 해당하며, (3) 구문의미이해력 검사(Pae et al., 2004)의 원점수가 7세 평균을 기준으로 - $1 \mathrm{SD}$ 이상이 며, (4) 교사나 부모에 의해 약물을 복용하거나 기타 신체, 행동, 정 서, 심리 등에서 문제를 보이지 않으며, (5) 일반학급에 재학 중인 아 동으로 선정하였다. 연구 대상의 기본 정보를 Table 1에 제시하였다. 
Yun Ji Kwak, et al. • Metaphor Comprehension of School-Aged Children with Borderline Intellectual Functionling

Table 1. Participants' characteristics

\begin{tabular}{llcc}
\hline & $\mathrm{BIF}(\mathrm{N}=10)$ & $\mathrm{TD}(\mathrm{N}=10)$ & $t$ \\
\hline Age $(\mathrm{yr})$ & $10.14(.95)$ & $8.82(.59)$ & $3.755^{* *}$ \\
K-WISC-III (IO) & $77.00(3.27)$ & $99.10(5.32)$ & $-11.192^{* * *}$ \\
REVT & & & \\
RV & $89.90(4.63)$ & $92.50(5.80)$ & -1.108 \\
EV & $91.30(3.89)$ & $94.90(5.67)$ & -1.657 \\
KOSECT & $49.20(2.94)$ & $51.60(2.50)$ & -1.967 \\
\hline
\end{tabular}

Values are presented as mean (SD).

$\mathrm{BIF}=$ children with borderline intellectual functioning; $\mathrm{TD}=$ typically developing children; K-WISC-III=Korean-Wechsler Intelligence Scale for Children III (Kwak, Park, \& Kim, 2001); IQ=total intelligence quotient (verbal, nonverbal); REVT=Receptive \& Expressive Vocabulary Test (Kim, Hong, Kim, Jang, \& Lee, 2009); RV= receptive vocabulary; EV = expressive vocabulary; KOSECT = Korean Oral Syntax Expression Comprehension Test (Pae, Lim, Lee, \& Jang, 2004).

${ }^{* *} p<.01,{ }^{* * *} p<.001$.

연구에 참여한 아동의 학년 분포는 일반아동은 2,3 학년 각각 5 명 이었고, 경계선 지능 아동은 3 학년 5 명, 4 학년 3 명, 5 학년 2명이었다.

두 집단 간에 생활연령 $(t=3.755, p<.01)$ 과 전체지능 지수 $(t=$ -11.192, $p<.001)$ 는 유의한 차이가 있었으나, REVT 수용어휘 $(t=$ $-1.108, p>.05)$, REVT 표현어휘( $t=-1.657, p>.05)$, 구문의미이해력 검사 $(t=-1.967, p>.05)$ 에서는 유의한 차이가 나타나지 않았다.

\section{연구 도구}

본 연구에서 사용된 은유 이해 과제의 문장형태는 선행연구 (Byun \& Choi, 2000; Hong, 2001; Lim, 2010)를 참고하였으며, 일부 문장은 제작하였다. Kim (2003)의 등급별 국어교육용 어휘에 수록 된 1,2 등급 어휘와 초등학교 교과서 어휘 조사 연구(Kim, 2009)의 1-3학년 어휘를 사용하여 제작하였다. 은유문장 형태는 'A는 B이 다', ' $\mathrm{OO}$ 의 $\mathrm{A}$ 는 $\mathrm{B}$ 이다'를 유지하고 문맥의 길이는 아동의 언어 연령 을 고려하여 초등학교 2,3 학년 읽기, 쓰기 교과서의 구문구조로 4-7어절, 8-24음절로 문맥을 구성하였다. 비문맥 조건은 은유문장 만 제공되었으며 문맥 조건은 대화 주고받기 상황을 표현한 언어문 맥에서 은유문장이 제시되었다. 대화 횟수는 3-4회로 첫 번째 혹은 두 번째 발화에서 은유적 표현을 유추할 수 있는 문장을 제시하는 형식이었고 일상생활에서 접하는 친숙한 상황의 문맥을 구성하였 다. 아동이 적절한 의미를 선택할 수 있도록 보기를 제시하였다. 보 기는 선행연구(Heo et al., 2012; Kim, 2015)를 참고하였으며, 아동 의 연령을 고려하여 (1) 은유 문장의 바른 해석, (2) 문자적(literal) 오류(매개어가 포함된 문자적 오류), (3) 관련 없는 오류로 구성하였 다. 이때 문자적 오류는 문항별 보기의 통일성을 위해 매개어가 포 함된 문자적 오류로 설정하였다. 이러한 방식으로 은유문장 44 개 를 사용하여 문맥 조건 44 문항, 비문맥 조건 44 문항 총 88 문항을
제작하였고 과제의 적절성을 평가하기 위해 본 연구의 대상 선정 기준과 일치하는 일반아동 4 명을 대상으로 예비검사를 실시하였 다. 예비검사를 통해 과제가 대상 아동의 언어연령에 적합한지를 살펴보았고 4 명 중 3 명이 오반응 한 문항은 수정·보완하였으며, 일 부 문항은 삭제하였다. 그런 다음 수정한 검사문항의 적절성을 알 아보기 위해 석사 이상의 언어치료사 3 명을 대상으로 문항에 사용 된 은유적 표현 및 보기에 대하여 연령에 적합한지, 맥락이 적절한 지를 5 점 척도를 이용하여 검증받았다. 검증 결과 평균 2점 이하의 은유 문장 및 보기의 경우 제외하였으며, 평균 3점 이하의 경우 수 정 및 보완하였다.

이 과정을 통해 최종적으로 본 문항에 사용된 은유문장은 36 개 였으며 은유문장만 제시된 비문맥 조건 36문항과 동일한 은유문 장이 포함된 문맥 조건 36 문항으로 총 72 문항을 제작하였다. 문맥 유무에 따른 은유문장은 중복 제시로 인한 학습효과를 배제하기 위해 $\mathrm{A}$ 세트와 $\mathrm{B}$ 세트로 구분하였다. 즉, 각 세트당 비문맥 조건 18 문항, 문맥 조건 18 문항으로, 문맥 유무조건에서 같은 은유가 포함 되지 않도록 구성하였다. $\mathrm{A}$ 세트의 문맥 조건의 문장은 $\mathrm{B}$ 세트의 비 문맥 조건 문장으로, $\mathrm{A}$ 세트의 비문맥 조건의 문장은 $\mathrm{B}$ 세트의 문맥 조건의 문장으로 제작되었다. 이때 은유의 유형에 따라 이해에 차 이가 있음을 고려하여(Byun \& Choi, 2000; Heo et al,. 2012) 36개 문장에 대해 3 명의 언어치료사에게 심리적, 속성적, 시각적 은유로 구분하게 하였다(Heo et al., 2012). A, B세트의 난이도를 조절하기 위해 3 명의 언어치료사가 모두 심리적 은유라고 평가한 문항을 각 세트에 2개 문항씩 포함시켰으며 속성적 은유라고 동일하게 평가 한 문항 7 개씩, 시각적 은유라고 동일하게 평가한 문항 5 개씩을 각 세트에 포함시켰고 나머지 4 개씩의 문항은 치료사 간에 은유 종류 를 다르게 평가한 문항이었는데, 두 사람이 일치한 은유 종류를 기 준으로 최대한 유사하게 분포시켰다. 그리고 $\mathrm{A}, \mathrm{B}$ 세트의 구문구조 는 'A는 B이다' 10 문항, 'OO의 $\mathrm{A}$ 는 $\mathrm{B}$ 이다' 8 문항으로 구성되었다. 또한 A, B세트의 어휘 분포는 $\operatorname{Kim}$ (2003)의 등급별 국어교육용 어 휘에서 확인한 기준으로 1 등급 $82 \%, 2$ 등급 $18 \%$ 정도였으며, 초등 학교 교과서 어휘 조사 연구(Kim, 2009)의 학년별 어휘에서 사용 된 어휘 중 1,2 학년 어휘 이외에 3 학년 어휘 수는 $\mathrm{A}$ 세트 10 개, $\mathrm{B}$ 세 트 9개였다. 은유 과제의 예는 Appendix 1에 제시하였다.

\section{연구 절차}

본 검사는 아동의 집이나 치료실 등의 분리된 공간에서 개별적 으로 실시하였으며 연구자 본인이 직접 시행하였다. 두 집단 모두 각 집단별로 아동의 반은 $\mathrm{A}$ 세트를 사용하였고 나머지 반은 $\mathrm{B}$ 세트 를 사용하여 검사하였다. 검사를 실시하기 전에 연습문항을 아동 
Table 2. Descriptive statistics of metaphor comprehension performance by group

\begin{tabular}{lll}
\hline & $\mathrm{BIF}(\mathrm{N}=10)$ & $\mathrm{TD}(\mathrm{N}=10)$ \\
\hline Non-contextual condition & $10.60(1.35)$ & $15.20(1.55)$ \\
Contextual condition & $14.50(1.43)$ & $17.60(0.70)$ \\
\hline
\end{tabular}

Values are presented as mean (SD).

$\mathrm{BIF}=$ children with borderline intellectual functioning; $\mathrm{TD}=$ typically developing children.

에게 제시하여 과제 이해를 도왔다. 연습문항에서 아동이 오답을 선택할 경우 충분히 설명하고 이해시킨 뒤 본 검사문항을 실시하 였다. 검사자는 아동에게 검사지를 보여주고 "제시된 문장을 읽고 같은 의미로 쓰인 문장을 보기에서 선택하세요.”라고 동일하게 지 시하였다. 연구 참여 아동은 모두 일반학급에 재학 중인 아동으로 특수교육 서비스를 받지 않고 있었고 읽기가 가능하였으나 읽기 능 력의 차이에서 올 수도 있는 영향을 배제하기 위하여 연구자가 모 든 문항 및 보기를 읽어주었다. 또한 아동이 선택한 보기는 검사자 가 직접 검사 기록지에 기록하였다. 과제를 수행하는 데 소요된 시 간은 약 25 분이었다.

\section{자료 분석 및 처리}

은유 과제는 문맥 유무에 따라 각 18 문항씩 총 36 문항이었다. 각 문항당 은유적 바른 해석의 정답은 1 점, 오답은 0 점으로 처리하였다. 문맥 유무에 따라각 18 점, 전체점수는 36점 만점으로 계산하였다.

경계선 지능 아동 집단과 일반아동 집단 간에 문맥 유무에 따른 은유이해에차이가 있는지 알아보기 위해 이원혼합분산분석(mixed two-way ANOVA)을 실시하였다. 통계적 검증은 SPSS Ver. 18.0 for Window를 사용하였다.

\section{연구 결과}

경계선 지능 아동과 언어연령 일치 일반아동의 은유 이해 과제 에 대한 기술 통계는 Table 2와 같다.

경계선 지능 아동과 일반아동 집단의 문맥 유무에 따른 은유이해 점수에 대해 집단과 문맥 유무의 이원혼합분산분석(mixed twoway ANOVA)을 실시한 결과, 은유 이해에 있어서 집단에 대한 주 효과가 유의하였고 $\left(F_{(1,18)}=57.688, p<.001\right)$ 문맥 조건의 주효과 역 시 유의한 것으로 나타났으며 $\left(F_{(1,18)}=121.915, p<.001\right)$, 집단 $\times$ 문맥 유무 조건의 상호작용 효과 또한 유의한 것으로 나타났다 $\left(F_{(1,18)}=\right.$ $6.911, p<.05)$. 상호작용 효과를 확인하기 위한 두 집단의 문맥에 따른 은유 이해 수행력을 Figure 1에 제시하였다.

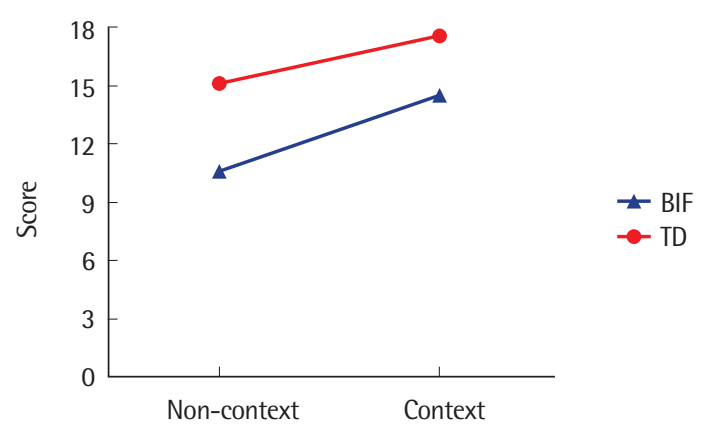

Figure 1. Metaphor comprehension performance by group. BIF=children with borderline intellectual functioning; TD= typically developing children.

\section{논의 및 결론}

본 연구에서는 언어연령이 만 7-8세인 학령기 경계선 지능 아동 과 언어연령을 일치시킨 일반아동을 대상으로 두 집단의 문맥 유 무에 따른 은유 이해 능력에 차이가 있는지를 알아봄으로써, 경계 선 지능 아동의 은유 이해 특성을 살펴보고자 하였다

첫째, 경계선 지능 아동과 언어연령을 일치시킨 일반아동의 은 유 이해 능력을 살펴보면, 경계선 지능 아동 집단이 일반아동 집단 에 비해 유의하게 낮은 점수를 받아 은유 이해에 어려움이 있는 것 으로 나타났다. 은유 이해는 관련된 요인이 다양하고 그러한 요인 들의 상호작용에 의해 이루어지므로 경계선 지능 아동이 일반아 동에 비해 더 어려움을 겪을 것임을 예상할 수 있다. 대표적인 원인 으로는 경계선 지능 아동의 낮은 지능으로 인한 상위언어능력의 결 함이 의미추론의 발달에 영향을 준 것으로 볼 수 있다(Malgady, 1977; Masi et al., 1998; Reis et al., 2000). 은유를 포함한 비유적 언 어능력은 다른 지적 기능들과 관련되는 요인으로 언어적 창의성, 언어성 지능, 읽기 이해, 학습 성취 등과 관련이 높은 것으로 알려져 있다(Malgady, 1977). 경계선 지능 아동이 지닌 언어적 창의성, 언 어성 지능, 읽기 이해력의 문제 등은 은유 이해에 어려움으로 영향 을 끼칠 것임을 예상할 수 있다. Vosniadou (1989)에 의하면 은유에 대한 이해는 개인이 지닌 스크립트, 쉐마, 정신적 모델 등 기억에 저 장된 지식을 포함하는 내적 문맥과 물리적 환경, 언어적 문맥 등으 로 구성되는 외적 문맥의 상호작용에 의해 이루어진다고 하였는데, 경계선 지능 아동의 취약한 인지적 기능은 실제 생활경험의 개념 화를 방해하고 개인이 외부세계와 관계 맺는 데 있어서 어려움을 초래하여(Masi et al., 1998) 개인 내적인 스크립트, 쉐마, 지식 등의 축적을 어렵게 하고 이는 은유 이해에 방해가 될 것이다. 또한 은유 이해 능력은 은유적 표현의 주제어와 매개어가 포함하고 있는 유사 한 특성을 인식하는 유추능력과 관련이 높은데(Reynolds \& Orto- 
Yun Ji Kwak, et al. • Metaphor Comprehension of School-Aged Children with Borderline Intellectual Functionling

ny, 1980) 경계선 지능 아동은 지적장애 아동과 유사하게 이러한 능력의 부족으로(Ezell \& Goldstein, 1991; Kim, 2015; Nippold \& Fey, 1983) 은유 이해에 어려움이 가중될 수 있을 것이다. 비유 언어 를 이해하기 위해서 청자는 화자가 의도한 의미를 인식하고 추론하 여 해석할 수 있는 능력, 상황을 이해하는 능력이 필요하다(Choi, 1997; Nippold, 2007; Vosniadou, 1989). 이러한 측면에서 경계선 지 능 아동이 보이는 사회적 미성숙, 집중력 부족(Jung \& Lee, 2005), 정서를 다루는 능력의 부족, 개인과 외부세계의 관계 맺음의 어려 움(Masi et al., 1998)은 경계선 지능 아동의 은유 이해력에 영향을 끼쳤을 가능성이 있다.

둘째, 두 집단 모두 문맥이 제시되지 않은 비문맥 조건보다 대화 상황의 언어 문맥이 제시된 문맥 조건에서 유의하게 높은 수행을 보였다. 이는 일반적으로 은유 표현이 단독으로 제시되었을 때보다, 문맥 조건에서 제시되었을 때 은유적 의미를 더 잘 이해하였음을 의미한다. 이러한 결과는 문맥이 아동의 은유 이해에 도움을 준다 는 선행연구들(Byun \& Choi, 2000; Cha, 2006; Highnam et al., 1999; Kim, 2015; Norbury, 2005; Reynolds \& Ortony, 1980; Shin \& Kwon, 2010)의 결과와 일치한다. 본 연구에서 사용한 문맥은 일상 생활에서 접할 수 있는 상황을 대화식 언어 맥락으로 구성한 것이 었다. 일반아동과 경계선 지능 아동 모두 비문맥 조건에 비해 대화 식 언어 문맥에서 과제 수행력이 유의하게 향상되었다. 은유에 대 한 이해는 상상력과 밀접한 관련이 있으므로 청자의 언어 경험이 중요하고(Kim, 1997) 심상에 떠올리기 쉬운 과제일수록 더 잘 이해 될 수 있을 것이다. 따라서 일상생활에서 접할 수 있는 상황을 대화 식 언어 문맥으로 제공함으로써 아동이 지닌 쉐마, 스크립트 등이 활성화되어 심상에 상황을 떠올리도록 돕고, 대화 상황을 이해하 게 하여 문장에 내포된 의도를 파악하고 이해하는 데 도움을 줄 수 있었을 것이다.

한편 경계선 지능 아동이 새로운 단어의 의미를 추론할 때는 정 의 제공 조건에 비해 문맥 제공 조건에서 다소 낮은 수행을 보여, 문 맥을 잘 활용하지 못하는 것으로 나타났는데(Kim et al., 2016), 이 러한 결과를 비교해 볼 때, 경계선 지능 아동에게 문맥을 제공할 때 에는 구체적인 과제에 따라 달라져야함을 알 수 있다.

셋째, 집단과 문맥 조건의 상호작용 효과가 유의하였다. 두 집단 모두 문맥 조건에서 비문맥 조건에 비해 은유 이해 수행력이 유의 하게 높았는데, 문맥 유무에 따른 은유 이해 수행력의 차이는 두 집 단 간에 서로 달랐다. 본 연구에서 제시된 은유 표현 문장은 일상생 활에 사용되는 관습적 대화상황 문맥이 포함되었기 때문에 일반 아동의 경우 비문맥 조건에서도 대체로 높은 점수를 획득하였고, 문맥 조건에서는 천정효과를 보여 결과적으로 비문맥 조건과 문맥
조건의 수행 차이가 경계선 지능 아동에 비해 상대적으로 적게 나 타났다고 볼 수 있다. 즉, 본 연구 과제는 경계선 지능 아동에게는 과제의 난이도가 대체로 적절하였으나, 일반아동에게는 쉬운 편에 속하였을 수 있다. 이는 타당도 검사 및 예비 실험에서, 창의적인 은 유 표현과 같은 난이도가 높은 은유적 표현을 제외한 것이 영향을 미쳤을 수 있다. 두 집단의 언어연령을 일치시켰으나, 일반아동의 경우 경계선 지능 아동에 비해 높은 지적 수준을 보일 뿐만 아니라 상위언어능력으로 인하여 비문맥 조건에서도 은유의 기본 속성을 인지하여 의미 추론을 적절히 할 수 있었고 결과적으로 비문맥 조 건에서도 대체로 높은 수행을 보였던 것으로 볼 수 있다.

위의 결과를 종합해보면, 경계선 지능 아동은 일반아동에 비해 은유 이해에서 저조한 수행을 보이며, 두 집단 모두 비문맥 조건보 다 대화식 언어 문맥 조건에서 더 높은 수행을 보였다. 이는 두 집단 모두 은유와같은 비유적 표현에 함축된 의미를 추론하기 위해서는 대화식 언어 문맥을 활용하는 것이 효과적이라는 것을 시사한다.

본 연구는 참여 인원이 적었으므로 연구결과를 제한적으로 해 석하여야 할 것이다. 또한 과제에서 사용된 은유 문장의 경우, 선행 연구에 사용된 것을 바탕으로 하여 과제를 제작하였으나, 일반아 동 집단에게 은유 과제의 난이도가 낮았을 수 있다. 과제를 구성함 에 있어서 어휘, 문장구조, 은유 종류를 기준으로 난이도를 조절하 였으나 친숙도 측면을 고려하지 못한 제한점이 있다. 후속 연구에 서는 과제의 난이도를 높이고 친숙도를 고려하여 다루어야 할 것이 다. 본 과제에서 사용된 대화상황 언어 문맥뿐만 아니라 다양한 방 식의 문맥을 구성하여 효과를 비교해보는 것도 필요할 것이다. 은 유 이해의 능력은 학령전기부터 성인기에 이르기까지 점진적으로 향상되므로(Hong, 2001; Nippold \& Sullivan, 1987) 여러 연령대의 경계선 지능 아동의 은유 이해 능력을 조사하여 이들의 은유 이해 의 발달과정을 알아보는 것도 의미있는 연구가 될 것이다.

\section{REFERENCES}

American Psychiatric Association (2000). Diagnostic and statistical manual of mental disorders, fourth edition, text revision (DSM-IV-TR). Washington, DC: Author.

Billow, R. M. (1975). A cognitive developmental study of metaphor comprehension. Developmental Psychology, 11, 415-423.

Byun, Y. H., \& Choi, K. S. (2000). Development of metaphor comprehension depending on contextual clue and metaphor type. Korean Journal of Human Development, 7, 49-64.

Cha, Y. S. (2006). A comparative study on metaphors comprehension by differ- 
ent cues in school-age children with language delay (Master's thesis). Dankook University, Yongin, Korea.

Choi, Y. H. (1997). The role of metalinguistic ability in Korean language education. Korean Language Education Research, 7, 81-106.

Chung, H. S. (2002). A study on elementary school student's understanding of indirect expressions. The Korean Language and Literature, 132, 89-119.

Ezell, H. K., \& Goldstein, H. (1991). Comparison of idiom comprehension of normal children and children with mental retardation. Journal of Speech, Language, and Hearing Research, 34, 812-819.

Heo, A. K., Lim, J., \& Hwang, M. (2012). The comprehension of metaphors and simile in children with specific language impairment. Journal of Speech \& Hearing Disorders, 21, 209-225.

Highnam, C., Wegmann, J., \& Woods, J. (1999). Visual and verbal metaphors among children with typical language and language disorders. Journal of Communication Disorders, 32, 25-35.

Hong, Y. H. (2001). Comprehension of metaphor between the specific language impaired and the normal children (Master's thesis). Ewha Womans University, Seoul, Korea.

Jung, H. J., \& Lee, J. Y. (2005). The analysis on the cognitive, behavior characteristics of the borderline intellectual functioning children. Korean Journal of Child Welfare, 3, 109-124.

Kim, E., Hwang, M., \& Ko, S. (2016). Inference of word meaning in accordance with definition presentation and context presentation for children with borderline intellectual functioning. Communication Sciences \& Disorders, 21, 262-270.

Kim, H. P. (2012). The ability of shadowing speaking of sentences which have different lengths and structures by the children who have borderline intelligence \& language developmental delay (Master's thesis). Dankook University, Yongin, Korea.

Kim, H. S. (2009). Research of the vocabulary of elementary school textbook. Seoul: National Institute of Korean Language.

Kim, J. H. (1997). An analysis of the effects of metaphor on imaginative thinking (Master's thesis). Hanyang University, Seoul, Korea.

Kim, J. Y., \& Kim, J. K. (2016). Reading subdomain characteristics of schoolaged children with borderline intellectual functioning. Journal of SpeechLanguage \& Hearing Disorders, 25, 67-76.

Kim, K. H. (2003). Grade level vocabulary list. Seoul: Pagijung.

Kim, K. H., \& Kim, D. I. (2007). Grade level differences in academic achievements of elementary students with borderline intellectual functioning. Proceedings of Fall Conference on the Korean Society of Special Education,
73-97.

Kim, M. M. (2002). The analysis of the development tendency of understanding of metaphors (Master's thesis). The Catholic University of Korea, Bucheon, Korea.

Kim, S. J. (2015). Comprehension of idioms in school-aged children with borderline intelligence (Master's thesis). Dankook University, Yongin, Korea.

Kim, Y. T., Hong, G. H., Kim, K. H., Jang, H. S., \& Lee, J. Y. (2009). Receptive \& expressive vocabulary test (REVT). Seoul: Seoul Community Rehabilitation Center.

Kwak, K. C., Park, H. W., \& Kim, C. T. (2001). Korean Wechsler intelligence scale for children-III (K-WISC-III). Seoul: Seoul Special Education Publishing Co.

Lazar, R. T., Warr-Leeper, G. A., Nicholson, C. B., \& Johnson, S. (1989). Elementary school teachers' use of multiple meaning expressions. Language, Speech, and Hearing Services in Schools, 20, 420-430.

Lee, H. J., \& Kim, M. (2015). The correlation between metaphor comprehension and reading comprehension of poor readers in 4-6 grades. Communication Sciences \& Disorders, 20, 331-343.

Leonard, L. B. (1998). Children with specific language impairment. Cambridge, MA: MIT Press.

Lim, J., \& Hwang, M. (2006). Grammaticality judgment and error correction by children with developmental language impairments. Speech Science, 13, $59-72$.

Lim, J. (2010). The comprehension of figurative meaning in ADHD children with and without language impairment. Korean Journal of Communication Disorders, 15, 307-320.

Madden, N. A., \& Slavin, R. E. (1983). Effects of cooperative learning on the social acceptance of mainstreamed academically handicapped students. Journal of Special Education, 17, 171-182.

Malgady, R. G. (1977). Children's interpretation and appreciation of similes. Child Development, 48, 1734-1738.

Masi, G., Marcheschi, M., \& Pfanner, P. (1998). Adolescents with borderline intellectual functioning: psychopathological risk. Adolescence, 33, 415-424.

Nippold, M. A. (2007). Later language development: school-age children, adolescents, and young adults (3rd ed.). Austin, TX: Pro-Ed.

Nippold, M. A., \& Fey, S. H. (1983). Metaphoric understanding in preadolescents having a history of language acquisition difficulties. Language, Speech, and Hearing Services in Schools, 14, 171-180.

Nippold, M. A., \& Sullivan, M. P. (1987). Verbal and perceptual analogical reasoning and proportional metaphor comprehension in young children. 
(a) Yun Ji Kwak, et al. • Metaphor Comprehension of School-Aged Children with Borderline Intellectual Functioning $\mathbf{J}$

Journal of Speech, Language, and Hearing Research, 30, 367-376.

Norbury, C. F. (2005). The relationship between theory of mind and metaphor: evidence from children with language impairment and autistic spectrum disorder. British Journal of Developmental Psychology, 23, 383-399.

Owens, R. E. (2005). Language development: an introduction (6th ed.). Boston, MA: Pearson.

Pae, S., Lim, S. S., Lee, J. H., \& Jang, H. S. (2004). Korean Oral Syntax Expression Comprehension Test (KOSECT). Seoul: Seoul Community Rehabilitation Center.

Reis, S. M., McGuire, J. M., \& Neu, T. W. (2000). Compensation strategies used by high-ability students with learning disabilities who succeed in college. Gifted Child Quarterly, 44, 123-134.

Reynolds, R. E., \& Ortony, A. (1980). Some issues in the measurement of children's comprehension of metaphorical language. Child Development, $51,1110-1119$.
Seo, J. S. (1982). A study of metaphor expression (Master's thesis). Ewha Womans University, Seoul, Korea.

Shin, H. N., \& Kwon, D. H. (2010). A study into the ability of children with nonverbal learning disabilities to interpret metaphor according to familiarity and story context. Journal of Speech \& Hearing Disorders, 19, 107-124.

Siltanen, S. A. (1989). Effects of three levels of context on children's metaphor comprehension. Journal of Genetic Psychology, 150, 197-215.

Tan, M., Barbot, B., Mourgues, C., \& Grigorenko, E. L. (2013). Measuring metaphors: concreteness and similarity in metaphor comprehension and gifted identification. Educational \& Child Psychology, 30, 89-100.

Vosniadou, S. (1989). Context and the development of metaphor comprehension. Metaphor and Symbol, 4, 159-171.

Yu, K., Jeong, E. H., \& Kim, R. H. (2007). Characteristics of language in the school-aged children with borderline intelligence. Journal of Special Children Education, 9, 193-209. 
Appendix 1. 은유 이해 과제 예시

\begin{tabular}{ll}
\hline A 세트 & \multicolumn{1}{c}{$B$ 세트 } \\
\hline 비문맥 제시 조건 & 비문맥 제시 조건 \\
시간은 화살이다. & 아영이는 딱따구리다. \\
1) 시간이 매우 빨리 갔다. & 1) 아영이는 시끄럽다. \\
2) 시간 안에 화살을 쏘았다. & 2) 아영이는 딱따구리를 보았다. \\
3) 시간이 갑자기 멈췄다. & 3) 아영이는 놀이터에 갔다. \\
문맥 제시 조건 & 문맥 제시 조건 \\
승기: 아까 전부터 계속 말하고 있는 사람 누구야? & 엄마: 내일 개학인데 방학숙제는 다 했니? \\
서영: 아영이 같은데? & 소민: 아직요, 방학한지 얼마 안 된 것 같은데.. \\
승기: 아, 아영이는 딱따구리구나. & 엄마: 그것 봐, 엄마가 시간은 화살이랬잖아. \\
1) 아영이는 시끄럽다. & 1) 시간이 매우 빨리 갔다. \\
2) 아영이는 딱따구리를 보았다. & 2) 시간 안에 화살을 쏘았다. \\
3) 아영이는 놀이터에 갔다. & 3) 시간이 갑자기 멈췄다. \\
\hline
\end{tabular}

1) 은유 표현의 바른 해석, 2) 매개어가 포함된 문자적(literal) 오류, 3) 관련 없는 오류. 


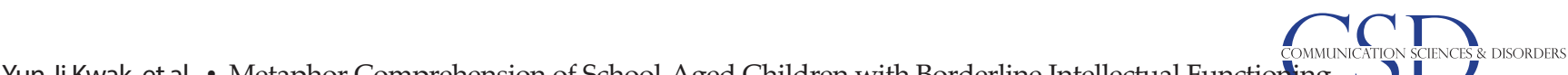

\section{국문초록}

\section{경계선 지능 아동의 문맥 유무에 따른 은유 이해 능력}

곽윤지 ${ }^{1} \cdot$ 황민아 $\cdot$ 정미란 ${ }^{3}$

단국대학교 일반대학원 언어병리학과, ${ }^{2}$ 단국대학교 특수교육과, ${ }^{3}$ 유원대학교 언어치료학과

배경 및 목적: 학령기 경계선 지능 아동의 은유 이해 능력을 알아보기 위하여 은유 문장만 제시되는 비문맥 조건과 대화상황의 언어문 맥이 제시되는 문맥 조건에서 일반아동과 경계선 지능 아동의 은유 이해 능력을 비교하였다. 방법: 언어 연령이 만 7-8세인 경계선 지능 아동 10 명과 언어연령을 일치시킨 일반아동 10 명, 총 20 명이 본 연구에 참여하였다. 연구 과제는 은유 문장만 제시된 비문맥 조건과 대 화상황 언어문맥이 제시된 문맥 조건 과제 각각 18 문항씩 총 36 문항으로 구성하였다. 문맥 유무의 조건에 따른 은유 문장은 중복되지 않도록 두 개의 세트를 구성하였다. 두 집단의 문맥 유무에 따른 은유 이해 능력을 비교하기 위하여 집단(2) $\times$ 문맥(2)의 이원혼합분산 분석을 실시하였다. 결과: 이원혼합분산분석 결과 집단, 문맥의 주효과가 유의하였으며 집단 $\times$ 문맥의 상호작용 효과 역시 유의하였다. 논의 및 결론: 경계선 지능 아동은 일반 아동에 비해 은유적 표현을 이해하는 데 유의하게 낮은 수행력을 보였으며 두 집단 모두 비문 맥 조건보다 문맥 조건에서 더 높은 수행력을 보였다. 대화상황의 언어적 문맥은 은유 이해를 돕는다는 것을 확인할 수 있었다. 본 연구 결과에 따라 연구의 시사점 및 제한점을 기술하였다.

핵심어: 경계선 지능 아동, 은유 이해, 문맥

본 논문은 제 1 저자의 석사학위논문을 요약한 것임.

\section{참고문헌}

곽금주, 박혜원, 김청택(2001). 한국판아동용웩슬러지능검사(K-WISC-III). 서울: 도서출판특수교육.

김광해(2003). 등급별 국어교육용 어휘. 서울: 도서출판 박이정.

김근하, 김동일(2007). 경계선급 지능 초등학생의 학년별 학업 성취 변화: 초등학교 저학년을 중심으로. 한국특수교육학회 추계학술대회 발표논문

집, 73-97.

김명미(2002). 은유 이해력의 발달 경향 분석. 가톨릭대학교대학원 석사학위논문.

김수진(2015). 학령기 경계선급 지능 아동의 관용어 이해능력. 단국대학교대학원 석사학위논문.

김영태, 홍경훈, 김경희, 장혜성, 이주연(2009). 수용·표현어휘력검사(REVT). 서울: 서울장애인종합복지관.

김은지, 황민아, 고선희(2016). 경계선급 지능 아동의 정의제시 조건과 문맥제시 조건에 따른 비단어 의미 추론 특성. 언어청각장애연구, 21, 262-270.

김정혜(1997). 상상적 사고에 미치는 은유의 효과 분석. 한양대학교대학원 석사학위논문.

김주영, 김자경(2016). 학령기 경계선 지적 기능 아동의 읽기 하위영역별 특성. 언어치료연구, 25, 67-76.

김한샘(2009). 초등학교 교과서 어휘 조사연구. 서울: 국립국어원.

김후비(2012). 경계선지능 언어발달지체 아동의 문장길이와 구조에 따른 문장 따라말하기 수행력. 단국대학교대학원 석사학위논문.

배소영, 임선숙, 이지희, 장혜성(2004). 구문의미이해력검사. 서울: 서울장애인종합복지관.

변윤희, 최경숙(2000). 문맥적 단서와 은유의 종류에 따른 아동의 은유 이해의 발달. 인간발달연구, 7, 49-64.

서정수(1982). 은유적 표현의 이해에 관한 일연구. 이화여자대학교대학원 석사학위논문.

신후남, 권도하(2010). 친숙의 정도와 이야기 문맥에 따른 비언어성 학습장애 아동의 은유이해 특성. 언어치료연구, 19, 107-124.

유경, 정은희, 김락형(2007). 학령기 경계선 지능 아동의 언어특성 연구. 특수아동교육연구, 9, 193-209.

이현정, 김미배(2015). 4-6학년 읽기부진아동의 은유이해능력과 읽기이해능력의 상관관계. 언어청각장애연구, 20, 331-343.

임종아(2010). 주의력결핍 과잉행동장애(ADHD)아동의 비유 의미 인식. 언어청각장애연구, 15, 307-320. 
임종아, 황민아(2006). 경계선지능 언어발달장애아동과 일반아동의 문법성 판단 및 오류수정: 조사를 중심으로. 음성과학, 13, 59-72.

정혜승(2002). 초등학생의 간접적 표현의 이해에 관한 연구: 은유와 속담을 중심으로. 국어국문학, 132, 89-119.

정희정, 이재연(2005). 경계선 지능 아동의 인지적, 행동적 특성. 아동복지연구, 3, 109-124.

차윤숙(2006). 단서제시 조건에 따른 학령기 언어발달지체 아동의 은유이해 능력 비교. 단국대학교대학원 석사학위논문.

최영환(1997). 상위언어적 능력의 국어교육적 의의. 국어교육학연구, 7, 81-106.

허애경, 임종아, 황민아(2012). 단순언어장애아동의 비유적 표현의 이해. 언어치료연구, 21, 209-225.

홍윤희(2001). 단순언어장애 아동과 정상 아동의 은유 이해능력 비교: 지각적 은유와 심리적 은유를 중심으로. 이화여자대학교대학원 석사학위논문. 